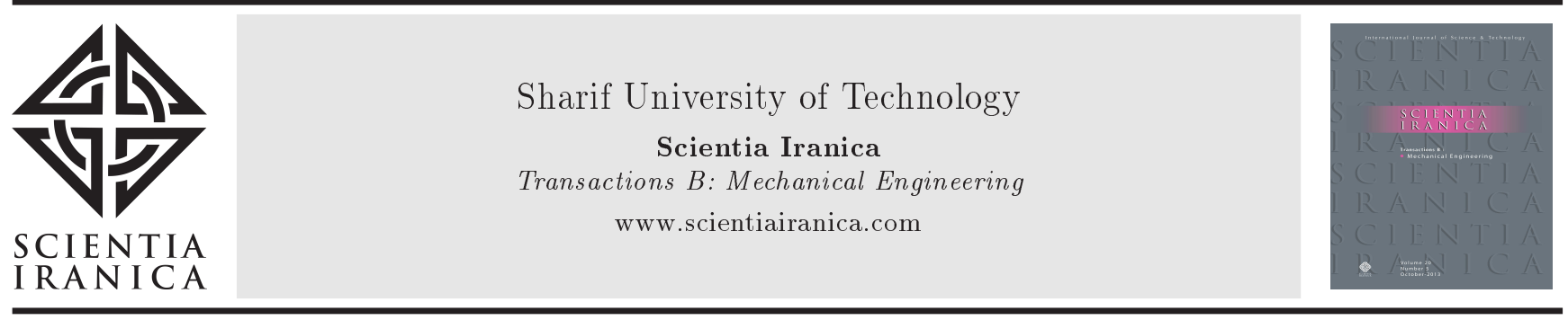

\title{
Effect of water-in-heavy fuel oil emulsion on the non-reacting spray characteristics under different ambient conditions and injection pressures: A CFD study
}

\section{H. Nowruzi and P. Ghadimi*}

Department of Marine Technology, Amirkabir University of Technology, Tehran, P.O. Box 15875-4413, Iran.

Received 20 December 2014; received in revised form 20 October 2015; accepted 11 January 2016

\author{
KEYWORDS \\ Non-reacting spray \\ characteristic; \\ Water in heavy fuel \\ oil emulsion; \\ Breakup; \\ High injection \\ pressure; \\ Back pressure.
}

\begin{abstract}
Emulsified fuel is one of the main strategies to substitute the conventional fossil fuel for the purpose of emission control and enhancement of fuel efficiency. Accordingly, non-reacting spray characteristics of water-in-Heavy Fuel Oil (HFO) emulsion are numerically investigated in the present study via CFD analysis. Three different volumetric percentages of water in HFO are investigated and compared with pure HFO. Effects of four different injection pressures on injected fuel spray characteristics are studied. Moreover, influences of three different ambient back pressures and two ambient temperatures are considered. For these purposes, the characteristics of spray penetration, cone angle, volume, and SMD are evaluated through the analyses of non-dimensional numbers. For modeling the interaction of the fuel discrete phase and the gaseous continuous phase, EulerianLagrangian multiphase formulation in OpenFOAM CFD toolbox is implemented. Fuel droplet tracking in Lagrangian scheme is applied by Lagrangian Particle Tracking method. Also, KH-RT as a hybrid breakup model for liquid fuel core breakup and standard model of $k-\varepsilon$ in RANS for turbulence modeling are utilized. Numerical results are validated against existing experimental data with suitable accordance. Longer spray penetration length, larger cone angle, and greater spray volume are achieved for the emulsified fuels.
\end{abstract}

(C) 2016 Sharif University of Technology. All rights reserved.

\section{Introduction}

Heavy-duty diesel engines, due to their capability in high power generation, are very useful in various scopes such as maritime industries. High emission of these engines is considered as a limiting factor for their development. Therefore, by establishing restrictive regulations for emission control by the international

* Corresponding author. Tel.: +98 2164543117 ;

Fax: +982166412495

E-mail addresses: h.nowruzi@aut.ac.ir (H. Nowruzi);

pghadimi@aut.ac.ir (P. Ghadimi) community, a global movement is shaped to do research on different strategies for reducing the emission.

Among the proposed strategies, in-cylinder techniques have been more appealing from the perspective of emission control and improvement of fuel efficiency. Increasing the injection pressure, lowering the intake temperatures, and Exhaust-Gas Recirculation (EGR) are some of these strategies [1].

There are different emissions from diesel engine exhaust. However, controlling the $\mathrm{NO}_{x}$ pollution is one of the most important issues that has attracted the researchers' attention. The most significant physical phenomenon that has exponential influence on the $\mathrm{NO}_{x}$ 
formation rate is higher temperature $[2,3]$. Consequently, Low Temperature Combustion (LTC) method with the aim of reducing the temperature in the combustion chamber has recently become interesting for some scholars $[4,5]$. While the addition of water to the combustion chamber is one of the in-cylinder strategies, it can also be stated that water in fuel emulsion is considered as a popular technique in the field of water adding methods [6].

Use of emulsified fuels in diesel engines, because of decreasing the peak of combustion flame temperature, leads to $\mathrm{NO}_{x}$ control. Furthermore, better airfuel mixture is achieved by longer ignition delay in the emulsified fuel. Ignition delay up to $30-60 \%$ in the emulsified fuel rather than pure diesel fuel was reported by laser-based study of Musculus et al. [7]. Moreover, improvement of atomization procedure and homogeneity in air-fuel mixture is anticipated by micro-explosion of water droplets in the emulsion [8]. Reacting characteristics of the emulsified fuel spray with volume percentages of $10 \%$ and $20 \%$ of water were experimentally investigated by $\mathrm{Huo}$ et al. [9] Increase of spray penetration length in the emulsified fuel was one of their findings. Ballester et al. [10] performed an experimental study on a semi-industrial scale on the combustion characteristics of heavy oilwater emulsion. In another study, the impact of applying water-in-diesel emulsion on $\mathrm{NO}_{x}$ and soot emissions was analyzed by Park et al. [11]. However, based on the cited literature, lack of indepth study on the non-reacting characteristics of emulsified fuel spray is quite evident. Therefore, the necessity of a phenomenological study on the spray characteristics of emulsified fuel under non-reacting condition is the main motivation for conducting the current study.

On the other hand, large diesel engines are commonly fueled by Heavy Fuel Oil (HFO). These heavy fuels, due to their low quality, produce high level of pollutions. Therefore, the usage of blended fuels created from HFO and alcohols, such as butanol, methanol, and ethanol, on spray characteristics and emissions has been investigated in several studies $[12,13]$. Accordingly, in the current study, Heavy Fuel Oil (HFO) is selected as a basic fuel in emulsion with water. Different volumetric percentages of water in HFO lead to different physical fuel properties that affect the injected spray behaviors. Hence, in the present study, the influences of three different volumetric percentages of water in emulsified fuel are considered.

From another view point, influence of the injection pressure and ambient condition of the combustion chamber, including ambient temperature and back pressure, is considered in the injected spray behavior and its non-reacting characteristics. Moreover, the increase of turbulence in combustion chamber by increasing the injection pressure leads to formation of a homogenous air-fuel mixture. This phenomenon was concluded by Nishida et al. [14] in an experimental study on the influence of high and ultra-high injection pressures on the spray penetration and SMD of diesel fuel. In another analytical and experimental study, non-reacting microscopic and macroscopic spray characteristics of biodiesels and diesel under ultra-high injection pressures of 100,200 , and $300 \mathrm{MPa}$ were studied by Wang et al. [15].

Liquid fuel spray interaction with aerodynamic force of continuous air phase in the combustion chamber is dependent on the ambient back pressure and temperature as well as spray flow condition. Hence, liquid fuel spray exhibits different behavior under various ambient and flow conditions $[16,17]$. Influence of high back pressure on spray characteristics of plain jet injector in the comprehensive range of $100 \mathrm{kPa}$ to $1600 \mathrm{kPa}$ was experimentally investigated by Yang et al. [18]. In their study, a monotonous reduction in SMD value was detected with an increase in back pressure. Roisman et al. [19] experimentally and theoretically studied the influence of ambient pressure on the penetration of a diesel spray. Effects of different fuel and ambient gas temperatures on diesel spray characteristics and influence of wide range of back pressures under liquid swirl injection were studied by Park et al. [20] and Chen et al. [21], respectively.

Characteristics of emulsified fuel spray under different ambient conditions are not well understood, especially under non-reacting and non-evaporating conditions. Therefore, one of the main novelties of the current study is the investigation of non-reacting spray characteristics of emulsified fuels under different conditions, including different injection pressures, chamber back pressures, and temperatures.

Nowadays, numerical software based on Computational Fluid Dynamics (CFD) is an efficient alternative tool to evaluate the fuel spray characteristics. Different commercial software such as KIVA [22], ANSYS FLUENT [23], and AVL FIRE [24] can be used to accomplish the intended task. However, development of an open source CFD toolbox, such as OpenFOAM, has recently received more attention $[25,26]$.

Significance of investigating the influence of emulsified fuel, ambient condition, and injection pressure on spray characteristics has been surveyed by the cited literature. Accordingly, in this paper, non-reacting characteristics of emulsified fuel under different ambient temperatures, back pressures, and injection pressures are numerically evaluated.

\section{Emulsion of water in $\mathbf{H F O}$}

As pointed out earlier, adding water to the combustion chamber is a strategy for emission control through LTC technique. In general, there are different methods for 
adding water to the combustion chamber. However, emulsified fuel has become a preferable method based on five criteria: relative $\mathrm{NO}_{x}$ reduction, effect on the PM emission, variability of water addition, lubricating oil dilution, and expenditure [27].

In the structure of water-HFO emulsion, droplets of one phase (water in the present study) are surrounded by sheets of the other fluid (HFO). In addition, very little amount of surfactant with physical characteristics similar to pure HFO is used for the formation of the emulsified fuel. Maximization of superficial contact area between two fluids by activation of these two fluid surfaces is the mechanism of surfactant for achievement of stable water and heavy fuel oil emulsion [28].

On the other hand, based on spatial distribution of water in basic fossil fuel, water-in-fuel and fuel-in water are two discrete fuel emulsions. Water-in-fuel emulsion is a better selection for the emulsified fuel in diesel engines [29] due to microexplosion of water droplets and small change in viscosity and physical characteristics of the emulsified fuels. Therefore, waterin-HFO is the selected concept for the emulsified fuel in the current study. To model water-in-HFO, the NASA Jannaf coefficients as thermo-physical properties of this emulsified fuel are calculated and implemented in the OpenFOAM open source CFD toolbox. Physical characteristics of two components of the tested emulsified fuel are displayed in Table 1.

\section{Technical description of the problem and governing equation}

\subsection{Physics of the liquid spray}

In the internal combustion engine, initially desired fuel as a liquid phase spray is injected into the gaseous environment of the combustion chamber. This liquid spray has three distinct structural zones: Atomization, dense spray, and dilute spray regions. In the atomization region, blobs as a massive continuous liquid agglomeration, ligaments, and small amount of droplets exist. Moreover, primary breakup in the form of disintegration of the liquid fuel core into ligaments as non-spherical liquid sheets and droplets occurs in this region. On the other hand, the secondary breakup leads to decomposition of blobs into ligaments and similarly, ligaments to the spherical droplets in the dense spray and dilute spray regions [30].

Table 1. Component of emulsified fuel properties.

\begin{tabular}{lcc}
\hline Physical characteristics & $\begin{array}{c}\text { Heavy } \\
\text { fuel oil }\end{array}$ & Water \\
\hline Viscosity at $20^{\circ} \mathrm{C}\left(\mathrm{m}^{2} \mathrm{~s}^{-1}\right)$ & $1.2 \mathrm{e}-5$ & $1.004 \mathrm{e}-6$ \\
Density at $20^{\circ} \mathrm{C}\left(\mathrm{kg} / \mathrm{m}^{-3}\right)$ & 895 & 895 \\
Surface tension $\left(\mathrm{Nm}^{-1}\right)$ & 0.029 & 0.0728 \\
\hline
\end{tabular}

\subsection{Computational procedure}

Eulerian-Lagrangian multiphase scheme is adopted in the current study for modeling fuel-air interaction in the combustion chamber. Behavior of continuous air phase is predicted by five partial differential equations in the Eulerian approach. Based on the study conducted by Nowruzi et al. [13], continuity equation, vector component of momentum conservation, and conservation of energy equations are solved in Eulerian approach. For turbulence modeling in Eulerian approach, standard turbulence model of $k-\varepsilon$ is used in the unsteady RANS equation. Conservation equations are discretized by FVM, and PIMPLE algorithm (combination of SIMPLE and PISO) is implemented for the velocity-pressure coupling in OpenFOAM software. In the current study, selected time step for time marching procedure is assumed to be $1.0 \times 10^{-6} \mathrm{~s}$.

Lagrangian Particle Tracking (LPT) scheme is applied for evaluation of non-spherical particles orientation and rate of rotation [30]. For this purpose, spray equation is used as the probability in the condition space of the randomized variables as in:

$$
\begin{aligned}
\frac{\partial f}{\partial t} & +\nabla_{x}(f u)+\nabla_{v}\left(f \frac{\partial u}{\partial t}\right)+\frac{\partial}{\partial r}\left(f \frac{\partial r}{\partial t}\right) \\
& +\frac{\partial}{\partial T}\left(f \frac{\partial T}{\partial t}\right)+\frac{\partial}{\partial y}\left(f \frac{\partial y}{\partial t}\right)+\frac{\partial}{\partial \dot{y}}\left(f \frac{\partial \dot{y}}{\partial t}\right) \\
& =\dot{f}_{c o}+\dot{f}_{b r} .
\end{aligned}
$$

The term $F=d V / d t$ illustrates the acceleration of a single droplet in Eq. (1) [30]. Also, the term $f\left(X, V, r, T_{d}, T, y, \dot{y}, t\right) d V d r d T_{d} d y d \dot{y}$ shows a probable number of droplets per unit volume. The source terms in Eq. (1) are contributions due to the effects of collision of the droplets and droplets breakup.

\subsection{Spray breakup modeling}

Generally, due to complexity of simulating the primary breakup in high density and pressure liquid core near the injector nozzle, initial droplets radius and spray angle are considered as initial conditions. Based on this assumption, blob method that presented by Reitz and Diwakar [31,32], which is a popular primary breakup model, is implemented for the primary breakup modeling in the current study.

On the other hand, there are different methods for modeling the secondary breakup as impressive procedure for simulating the high injection pressure. Two major dimensionless numbers including Weber and Reynolds numbers are defined in modeling the secondary breakup. The Weber number of the gaseous phase is defined as:

$$
\mathrm{We}_{g}=\frac{\rho_{g} u_{\mathrm{rel}}^{2} D_{d}}{\sigma}
$$

where $D_{d}$ is the diameter of the fuel droplet. Reynolds 
number is another dimensionless number for showing the effect of viscosity on the breakup procedure. The Reynolds number of gaseous phase is given by:

$$
\mathrm{Re}=\frac{u_{\mathrm{rel}} D_{d}}{\nu_{g}},
$$

where $\nu_{g}$ is the gas kinematic viscosity.

Nowadays, hybrid breakup model is implemented for modeling the comprehensive secondary breakup. One of these hybrid methods is KH-RT which combines the $\mathrm{KH}$ and RT instabilities.

Kelvin-Helmholtz (KH) model or a Wave model is presented by Reitz [33]. The idea behind this method is the Kelvin-Helmholtz instability growth analysis on the cylindrical liquid jet surface with primary radius of $r_{0}$. The wavelength $\left(\Omega_{\mathrm{KH}}\right)$ and growth rate $\left(\Lambda_{\mathrm{KH}}\right)$ of the fastest growing wave on the surface of the liquid jet are defined as:

$$
\begin{aligned}
& \Omega_{\mathrm{KH}}\left[\frac{\rho_{l} r_{0}^{3}}{\sigma}\right]^{0.5}=\frac{0.34+0.38 . \mathrm{We}_{g}^{1.5}}{(1+\mathrm{Oh})\left(1+1.4 . T^{0.6}\right)}, \\
& \frac{\Lambda_{\mathrm{KH}}}{r_{0}}=9.02 \frac{\left(1+0.45 . \mathrm{Oh}^{0.5}\right)\left(1+0.4 . T^{0.7}\right)}{\left(1+0.865 . \mathrm{We}_{g}^{1.67}\right)^{0.6}},
\end{aligned}
$$

where the dimensionless numbers $\mathrm{Oh}, T, \mathrm{We}_{g}$, and $\mathrm{We}_{l}$ can be measured as in:

$$
\begin{array}{ll}
\mathrm{Oh}=\frac{\sqrt{\mathrm{We}_{l}}}{\mathrm{Re}_{l}}, & \mathrm{~T}=\mathrm{Oh} \sqrt{\mathrm{We}_{g}}, \\
\mathrm{We}_{g}=\frac{\rho_{g} u_{\mathrm{rel}}^{2} r_{0}}{\sigma}, & \mathrm{We}_{l}=\frac{\rho_{l} u_{\mathrm{rel}}^{2} r_{0}}{\sigma} .
\end{array}
$$

Here, $\mathrm{Oh}$ and $\mathrm{T}$ are dimensionless Ohnesorge number and Taylor number, respectively. Moreover, the rate of change of the droplet radius in $\mathrm{KH}$ model is given by:

$$
\frac{d r}{d t}=-\frac{r_{0}-r_{c}}{\tau_{b u}},
$$

where $r_{c}$ is the radius of new droplet (child droplet) and $\tau_{b u}$ is the dimensionless time of breakup (characteristics of breakup time), and they are defined as follows:

$$
\begin{aligned}
& r_{c}=B_{0} \cdot \Lambda_{\mathrm{KH}}, \\
& \tau_{b u}=3.788 . B_{1} \frac{r_{0}}{\Lambda_{\mathrm{KH}} \cdot \Omega_{\mathrm{KH}}},
\end{aligned}
$$

where $\mathrm{KH}$ breakup model is valid when:

$$
B_{0} \cdot \Lambda_{\mathrm{KH}} \leq r_{0}
$$

In the RT model, the growth rate of the fastest growing wave $\left(\Omega_{\mathrm{RT}}\right)$ and the corresponding wavelength $\left(\Lambda_{\mathrm{RT}}\right)$, based on the study of Bellman and Pennington [34], is:

$$
\begin{aligned}
\Omega_{\mathrm{RT}} & =\sqrt{\frac{2}{2 \sqrt{3 \sigma}} \frac{\left[a\left(\rho_{l}-\rho_{g}\right)\right]^{3 / 2}}{\rho_{l}+\rho_{g}}}, \\
\Lambda_{\mathrm{RT}} & =C_{3} 2 \pi \sqrt{\frac{3 \sigma}{a\left(\rho_{l}+\rho_{g}\right)}} .
\end{aligned}
$$

Consequently, based on the study of Ghasemi et al. [35] that introduces the KH-RT model as a more accurate prediction for the secondary breakup, the KH-RT breakup model is utilized in the current study.

\subsection{Grid generation and validation}

To validate the non-reacting spray characteristics of water-in-HFO emulsion fuel, a grid resolution sensitivity analysis is initially conducted for $\mathrm{HFO}$ at injection pressures of 60 and $100 \mathrm{MPa}$. Subsequently, based on an adopted mesh structure, two major properties of spray penetration length and spray cone angle of HFO are computed and validated against the experimental data [36].

For grid resolution sensitivity analysis, four different fully structured meshes (ranging from coarse mesh resolution of $0.004 \mathrm{~m}$ to finer mesh resolution of $0.001 \mathrm{~m}$ ) are studied for injection pressures of 60 and $100 \mathrm{MPa}$ in Figures 1 and 2, respectively. Afterward,

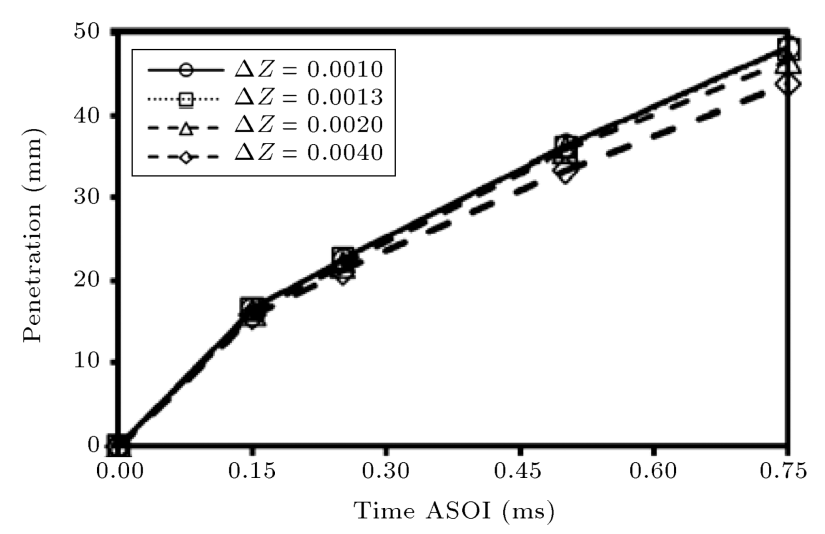

Figure 1. Grid independency test of HFO spray penetration length at injection pressure of $60 \mathrm{MPa}$.

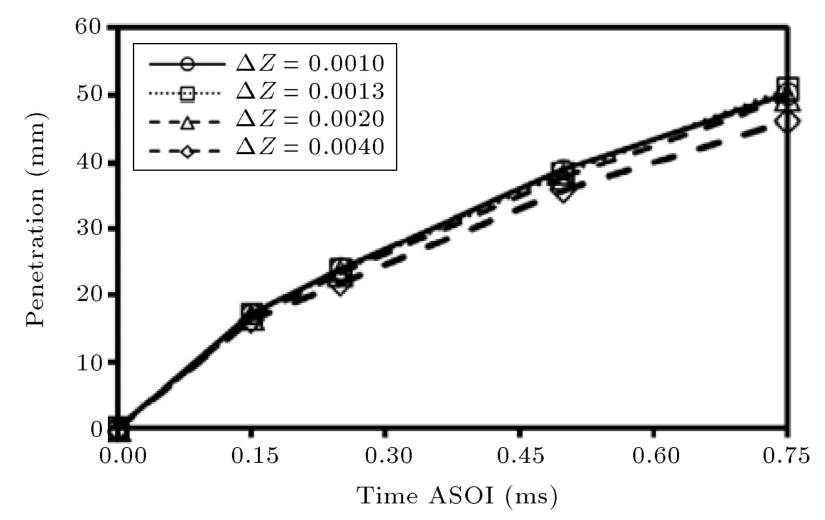

Figure 2. Grid independency test of HFO spray penetration length at injection pressure of $100 \mathrm{MPa}$. 

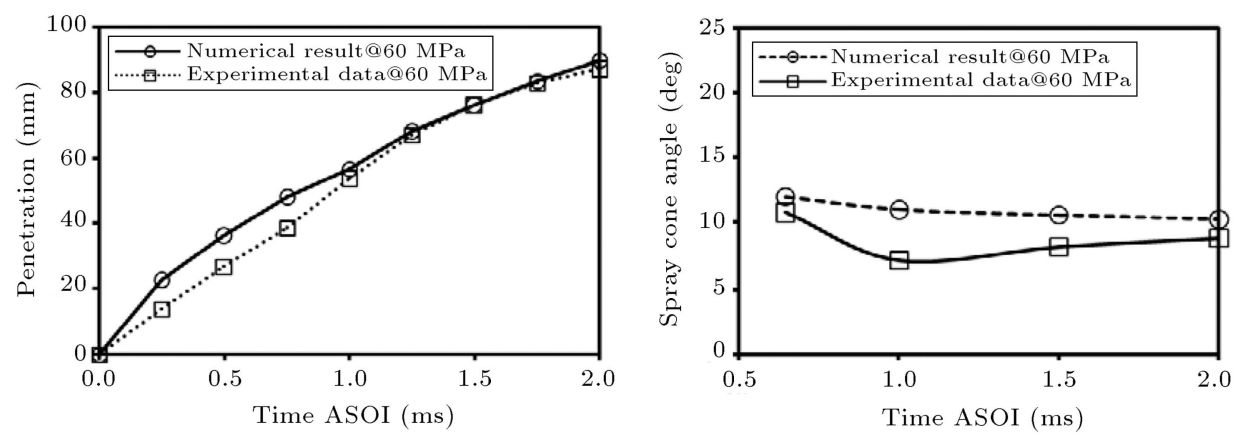

Figure 3. Comparison of numerical and experimental spray penetration length and spray cone angle of HFO at injection pressure of $60 \mathrm{MPa}[36]$.
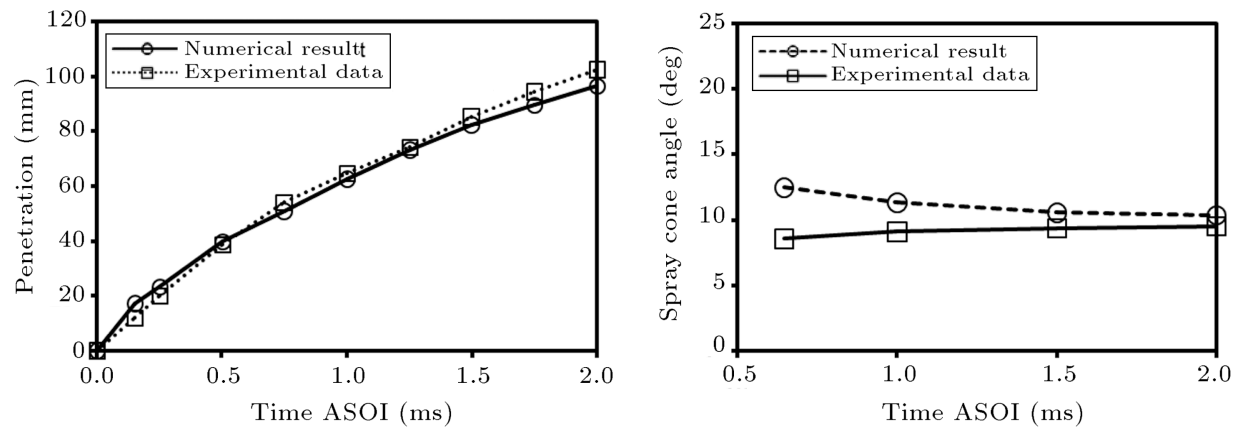

Figure 4. Comparison of numerical and experimental spray penetration length and spray cone angle of HFO at injection pressure of $100 \mathrm{MPa}$ [36].

by a selected proper mesh structure $(0.00133 \mathrm{~m})$, computational results of spray penetration length and spray cone angle of $\mathrm{HFO}$ at injection pressures of 60 and $100 \mathrm{MPa}$ are validated against experimental data [36] in Figures 3 and 4, respectively.

According to Figure 3, the RSME of penetration length and spray cone angle at injection pressure of $60 \mathrm{MPa}$ are 5.46 and 2.51, respectively. Moreover, based on Figure 4, the RSME of penetration length and spray cone angle at injection pressure of $100 \mathrm{MPa}$ are 3.21 and 2.34 , respectively.

Moreover, to demonstrate the accuracy of the selected numerical setup for modeling the emulsified fuels, a comparative study is conducted in Figure 5.

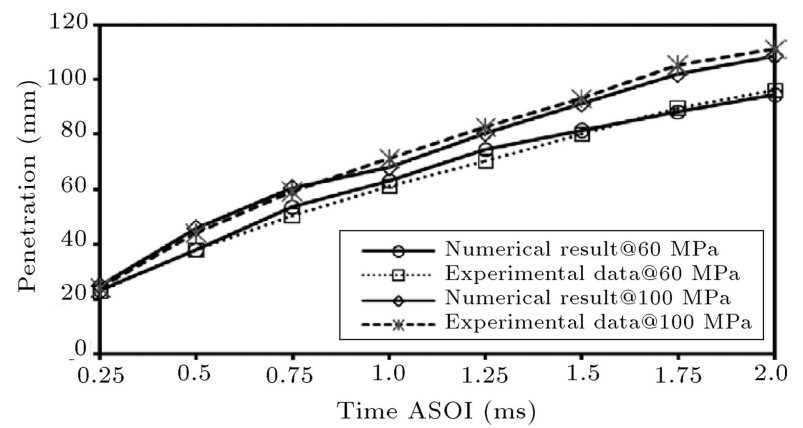

Figure 5. Comparison of numerical and experimental spray penetration length of diesel-water emulsion (by $18 \%$ volume percentage of water) at injection pressure of 60 and $100 \mathrm{MPa}$ [36].
As observed, suitable accordance is obtained between the current result and experimental data with RSME of 2.14 for $60 \mathrm{MPa}$ and 2.31 for $100 \mathrm{MPa}$.

\subsection{Numerical model specification and spray analysis criteria}

In the current study, water-in-HFO is injected to constant volume combustion chamber through a single hole injector. Injection mass flow rate for different ambient conditions and injection pressures is calculated based on the study of Pickett et al. [37]. The combustion chamber and injection setup of the present study are presented in Table 2.

To evaluate the behavior of the non-reacting liquid spray, we evaluated spray penetration length, spray cone, and SMD. Pictorial description of the liquid

Table 2. Combustion chamber and injection setup.

\begin{tabular}{clc}
\hline \multicolumn{2}{c}{ Model parameter } & Value \\
\hline \multirow{2}{*}{$\begin{array}{c}\text { Combustion } \\
\text { chamber }\end{array}$} & Length $(\mathrm{mm})$ & 450 \\
parameters & Back pressure (MPa) & 150 \\
& Ambient temperature $(\mathrm{K})$ & 1.4 \\
& Nozzle diameter (mm) & 0.27 \\
Injection & Fuel injection pressure (MPa) & 60 \\
parameters & Injection total mass (mg) & 34 \\
\hline
\end{tabular}




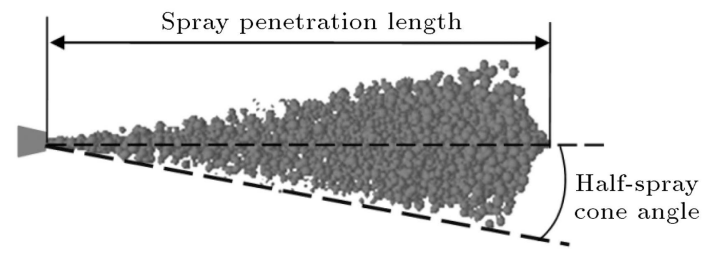

Figure 6. Definition of spray penetration length and half spray cone angle.

spray penetration length and half spray cone angle are provided in Figure 6.

Moreover, SMD as a targeted microscopic characteristic is calculated by the average diameter of all groups of droplets at a particular time.

\section{Results and discussion}

Numerical results and discussion of microscopic and macroscopic non-reacting spray characteristics of different water-in-HFO under different ambient conditions and injection pressures are presented in this section.

\subsection{Analysis on the non-dimensional number}

Three dimensionless numbers are considered for the present study: Weber (We) number, Reynolds number $(\mathrm{Re})$, and Ohnesorge number $(\mathrm{Oh})$. Relation between We and $\mathrm{Oh}$ numbers for all liquid droplets of HFOE0 (Pure HFO without water content) and HFOE20 (20\% water as an emulsion in $\mathrm{HFO}$ ) at $1.5 \mathrm{~ms}$ after the start of injection is illustrated in Figures 7 and 8 , respectively. Based on Figures 7 and 8, the minimum of Weber number is approximately the same for both utilized fuels. However, the maximum value of Weber number is larger for HFOE0 that indicates the higher effect of the surface tension in HFOE20. Also, Hardalupas et al. [38] proved that the magnitude of the Weber number indicates that droplet breakup is always limited to the leading edge of the fuel spray.

On the other hand, slight relocation in cloud droplet of $\mathrm{Oh}$ number toward larger value is evident for HFOE0. Therefore, it can be concluded that HFOE0

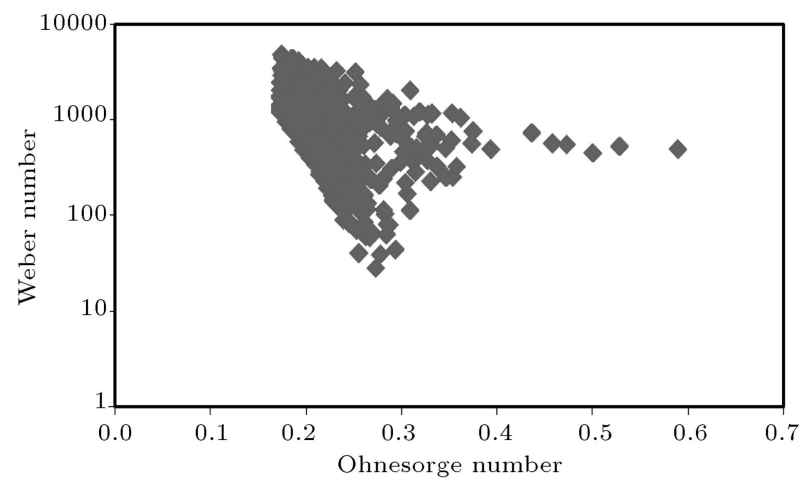

Figure 7. Weber number VS Ohnesorge number for HFOE0 at $1.5 \mathrm{~ms}$ after the start of ignition $\left(P_{\text {inj }}=60 \mathrm{MPa}, P_{\text {back }}=1.4 \mathrm{MPa}, T_{\mathrm{amb}}=298 \mathrm{~K}\right)$.

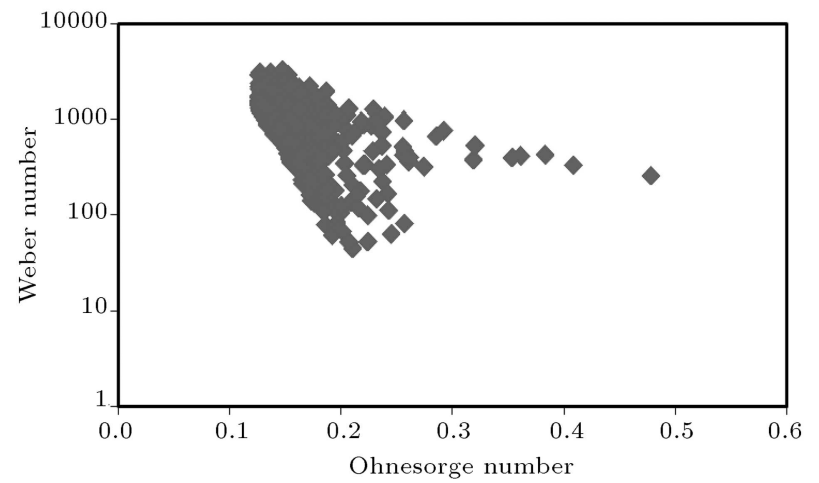

Figure 8. Weber number VS Ohnesorge number for HFOE20 at $1.5 \mathrm{~ms}$ after the start of ignition $\left(P_{\text {inj }}=60 \mathrm{MPa}, P_{\text {back }}=1.4 \mathrm{MPa}, T_{\mathrm{amb}}=298 \mathrm{~K}\right)$.

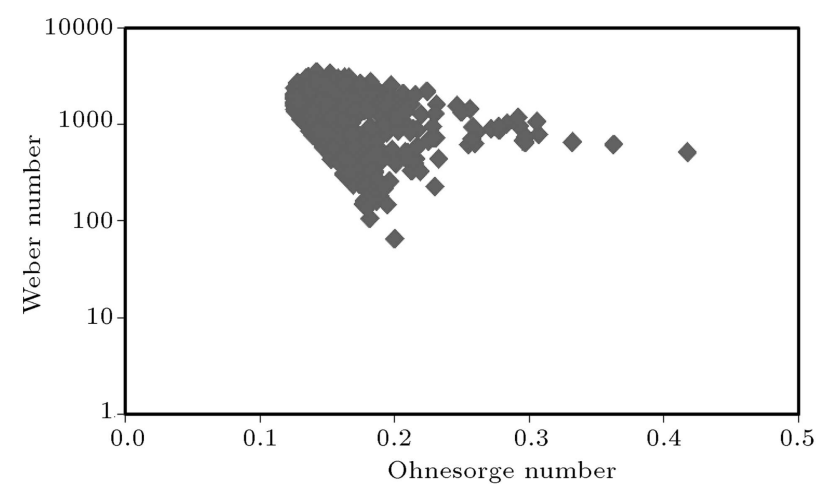

Figure 9. Weber number VS Ohnesorge number for HFOE20 at $1.5 \mathrm{~ms}$ after the start of ignition $\left(P_{\text {inj }}=300 \mathrm{MPa}, P_{\text {back }}=1.4 \mathrm{MPa}, T_{\mathrm{amb}}=298 \mathrm{~K}\right)$.

is more affected by the viscosity due to its larger Oh number.

Moreover, for studying the effect of injection pressure on the structure of We-Oh droplet cloud, the relation between We and $\mathrm{Oh}$ numbers for all liquid droplets of HFOE0 at injection pressure of $300 \mathrm{MPa}$, compared to that of HFOE20 at injection pressure of $60 \mathrm{MPa}$ in Figure 8, is presented in Figure 9. Slight enhancement in Weber number and insignificant change in the Ohnesorge number are detectable by an increase in the injection pressure from $60 \mathrm{MPa}$ to $300 \mathrm{MPa}$.

Influence of the injection pressure on the Re number for HFOE20 can be observed in Figure 10.

Based on Figure 10, Reynolds number exhibits a parabolic increase, when the injection pressure increases.

\subsection{Effect of volumetric percentage of water in emulsified fuel}

To study the influence of different volumetric percentages of water in the emulsified fuel, three different emulsified fuels with different volumetric percentages of water (as shown in Table 3 ) are compared with pure HFO. 


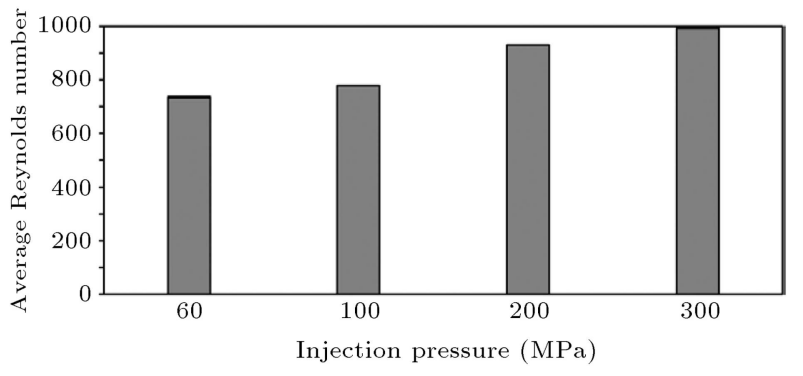

Figure 10. Average Reynolds number of HFOE20 for different injection pressure at $1.5 \mathrm{~ms}$ ASOI $\left(P_{\text {back }}=1.4 \mathrm{MPa}, T_{\mathrm{amb}}=298 \mathrm{~K}\right)$.

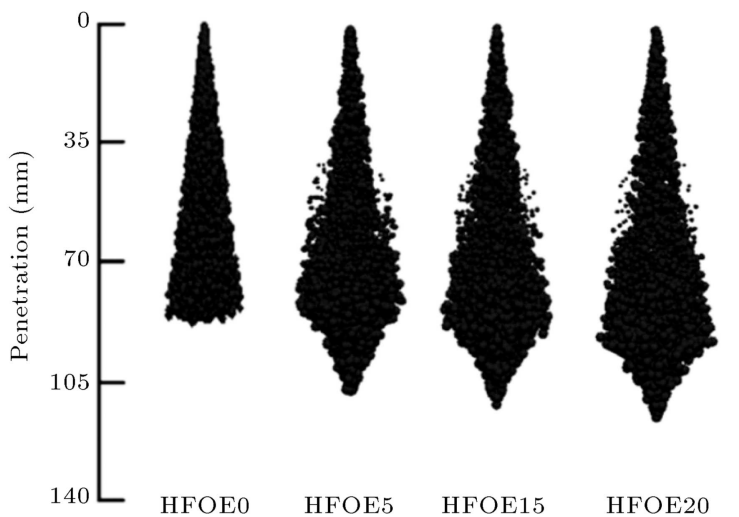

Figure 11. Liquid spray structure for different volumetric percentage of water in emulsified fuel at $1.5 \mathrm{~ms}$ after the start of ignition $\left(P_{\text {inj }}=60 \mathrm{MPa}, P_{\text {back }}=1.4 \mathrm{MPa}\right.$, $\left.T_{\mathrm{amb}}=298 \mathrm{~K}\right)$.

Table 3. Different volumetric percentages of water in emulsified fuel.

\begin{tabular}{ccc}
\hline Case & $\begin{array}{c}\text { Volumetric } \\
\text { percentage } \\
\text { of water }\end{array}$ & $\begin{array}{c}\text { Other } \\
\text { environmental } \\
\text { characteristics }\end{array}$ \\
\hline HFOE0 & $0 \%$ & $\begin{array}{l}\text { Injection pressure }=60 \mathrm{MPa} \\
\text { Back pressure }=1.4 \mathrm{MPa} \\
\text { Ambient temperature }=298 \mathrm{~K}\end{array}$ \\
\hline
\end{tabular}

Before studying the effects of different emulsified fuels, spray structure morphology for different volumetric percentages of water in the emulsified fuel at $1.5 \mathrm{~ms}$ after the start of injection is provided in Figure 11.

Based on Figure 11, bulkier spray with sharper tip is apparent in the emulsified fuel as opposed to the pure HFO (HFOE0). Also, these phenomenological changes are more significant in the emulsified fuel with more water content.

Subsequently, the effects of different volumetric percentages of water in the emulsified fuel on the spray characteristics are studied. For this purpose, spray penetration length, spray cone angle, spray volume, and Sauter Mean Diameter (SMD) for different volumetric percentages of water in the emulsified fuel are presented in Figure 12.
Based on Figure 12(a), it is found that all emulsified fuels with different volumetric percentages of water have longer spray penetration. Linear growing rate until $0.5 \mathrm{~ms}$ ASOI with asymptomatically trend after this time is detectable for both pure HFO (HFOE0) and all emulsified fuels. Also, HFOE20 with higher water content has insignificant longer spray penetration length than other emulsified fuels. This phenomenon can be the result of an increase in density and a decrease of dynamic viscosity in the emulsified fuel. However, due to the increase of surface tension of the emulsified fuel, the penetration length is not significant $[15,39]$. In addition, based on Figure 12(b), spray cone angle of the emulsified fuels is decreased in a temporal trend after the start of injection. Also, spray cone angle of the emulsified fuels has significantly greater value than that of HFOE0. Moreover, larger volume percentage of water content in the emulsion leads to an increase of spray cone angle, especially after $1.5 \mathrm{~ms}$. Also, HFOE5, as an emulsified fuel, offers a considerable longer spray cone angle than HFOA0. In the meantime, all emulsified fuels (HFOE5, HFOE15, and HFOE20) have approximately similar spray cone angles.

Based on spray volume in Figure 12(c), better recognition of air-fuel mixture study is prepared. Moreover, the addition of water content in the emulsified fuel causes greater spray volume, especially after $1.0 \mathrm{~ms}$. Consequently, a better homogeneity in air-fuel mixture is expected from the emulsified fuels due to larger penetration length, spray cone angle, and spray volume.

Based on Figure 12(d), emulsified fuels have larger SMD quantity, and an increase in volumetric percentage of water in the emulsion leads to larger SMD. This observation can be attributed to a significant decrease in the dynamic viscosity of the emulsified fuels rather than pure HFO.

\subsection{Effect of injection pressure on Emulsified fuel}

To study the effect of different injection pressures on liquid spray properties, four different injection pressures ranging from medium pressure of $60 \mathrm{MPa}$ to ultra-high pressure of $300 \mathrm{MPa}$ are considered. The influence of injection pressures is implemented for HFOE20 as the selected emulsified fuel and pure HFO (HFOE20) as presented in Table 4.

To study the effect of different injection pressures on the emulsified fuel spray morphology, liquid spray structure for different injection pressures of HFOE20 is illustrated in Figure 13 at $1.5 \mathrm{~ms}$ ASOI. Based on Figure 13, general perspective of the spray structure is approximately similar to HHFOE20 at different injection pressures. However, the fattest spray structure is detectable for HFOE20 at ultra-high injection pressure of $300 \mathrm{MPa}$. 


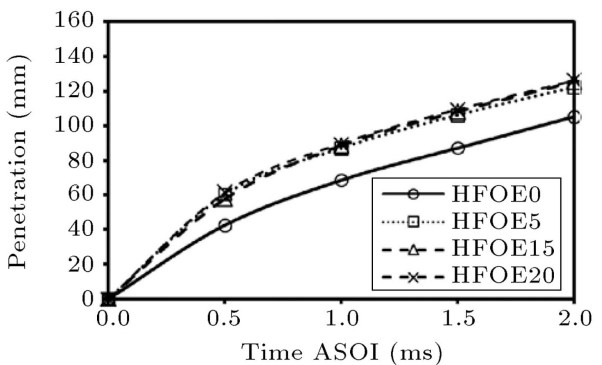

(a)

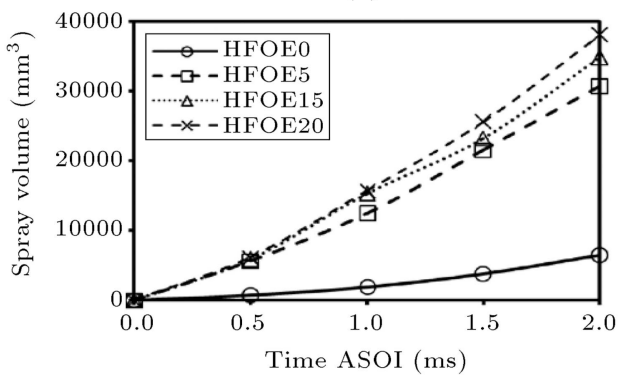

(c)

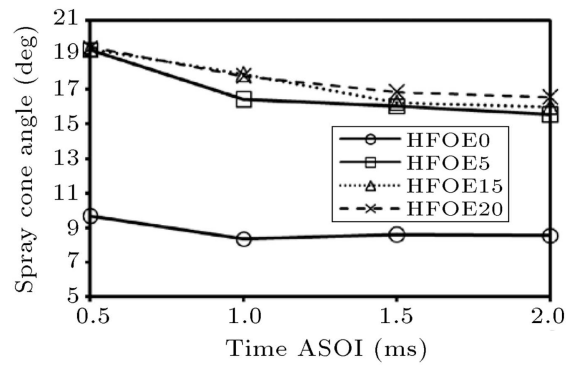

(b)

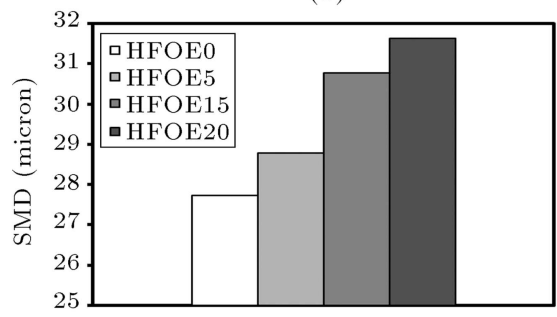

(d)

Figure 12. (a) Spray penetration length, (b) spray cone angle, (c) spray volume, and (d) SMD for different volumetric percentages of water in the emulsified fuel $\left(P_{\text {inj }}=60 \mathrm{MPa}, P_{\text {back }}=1.4 \mathrm{MPa}, T_{\text {amb }}=298 \mathrm{~K}\right)$.

Table 4. Cases of different injection pressures for HFOE0 and HFOE20.

\begin{tabular}{lcc}
\hline Case study & $\begin{array}{c}\text { Injection pressure } \\
(\mathbf{M P a})\end{array}$ & $\begin{array}{c}\text { Other environmental } \\
\text { characteristics }\end{array}$ \\
\hline HFOE0 @ $60 \mathrm{MPa}$ & 60 & \\
HFOE20 @ $60 \mathrm{MPa}$ & 60 & \\
HFOE0 @ $100 \mathrm{MPa}$ & 100 & Back pressure $=1.4 \mathrm{MPa}$ \\
HFOE20@ $100 \mathrm{MPa}$ & 100 & Ambient temperature $=298 \mathrm{~K}$ \\
HFOE0 @ $200 \mathrm{MPa}$ & 200 & \\
HFOE20 @ $200 \mathrm{MPa}$ & 200 & \\
HFOE0 @ $300 \mathrm{MPa}$ & 300 & \\
HFOE20 @ $300 \mathrm{MPa}$ & 300 & \\
\hline
\end{tabular}

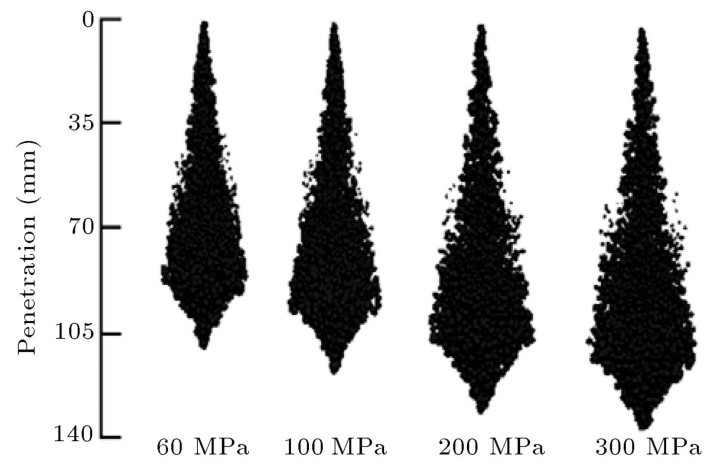

Figure 13. Liquid spray structure for different injection pressures of HFOE20 at $1.5 \mathrm{~ms}$ ASOI $\left(P_{\text {back }}=1.4 \mathrm{MPa}\right.$, $\left.T_{\mathrm{amb}}=298 \mathrm{~K}\right)$.

Macroscopic characteristics of spray penetration length, spray cone angle, spray volume, and microscopic criterion of Sauter Mean Diameter (SMD) for HFOE0 and HFOE20 at different injection pressures are displayed in Figure 14. Based on Figure 14(a), with homologous behavior, an increase in penetration length is detected with an increase in injection pressure for both HFOE0 and HFOE20. This happens because of the spray pressure augmentation related to ambient air resistance [14,15]. Also, insignificant effects of injection pressure increase on the spray penetration length of HFOE0 are evident until $0.5 \mathrm{~ms}$ ASOI. Furthermore, the use of HFOE20 instead of HFOE0 is proved to lead to a higher penetration length compared to the effect of increasing the injection pressure from $60 \mathrm{MPa}$ to $300 \mathrm{MPa}$ for HFOE0.

According to Figure 14(b), larger spray cone angle is observable in HFOE20 than HFOE0 at all injection pressures. However, increase in injection pressure has negligible effect on the spray cone angle of the emulsified fuels. However, greater spray cone angle is obtained in HFOE0 by increasing the injection pressure, especially for a pressure increase of 60 to $100 \mathrm{MPa}$. Based on Figure 14(c), an increase in injection pressure leads to larger spray volume for both 


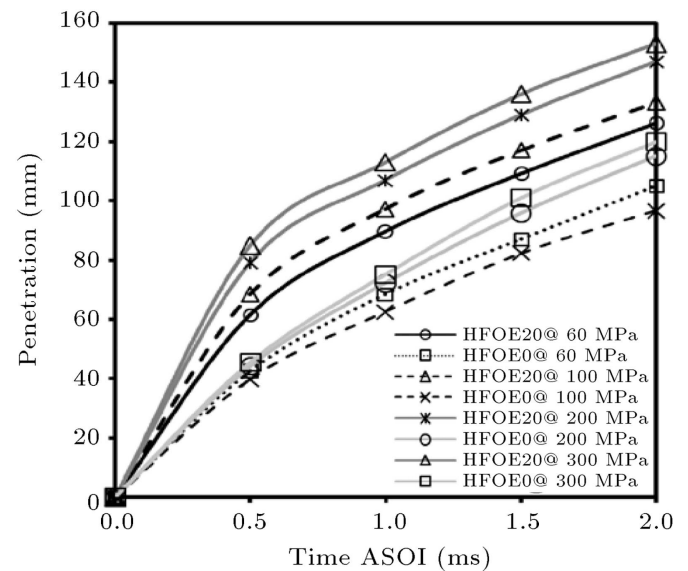

(a)

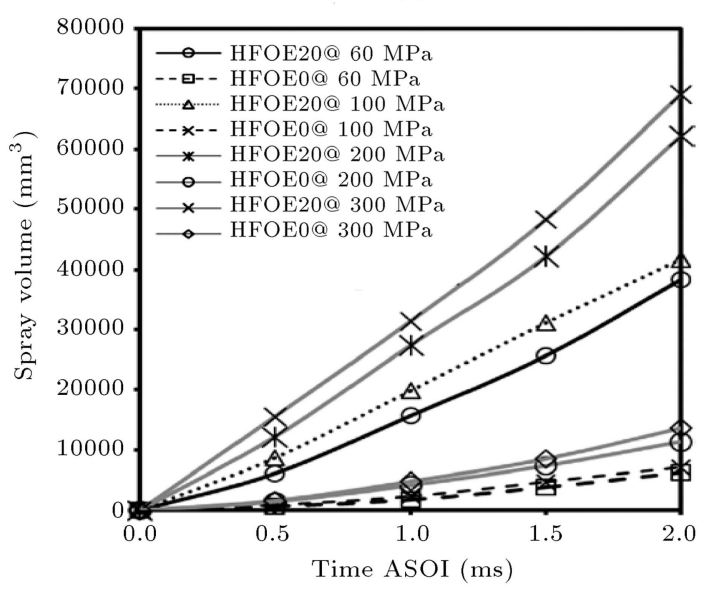

(c)

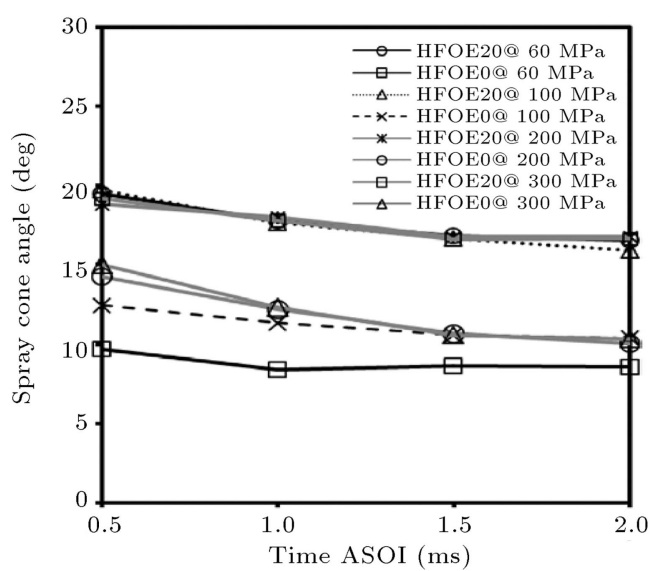

(b)

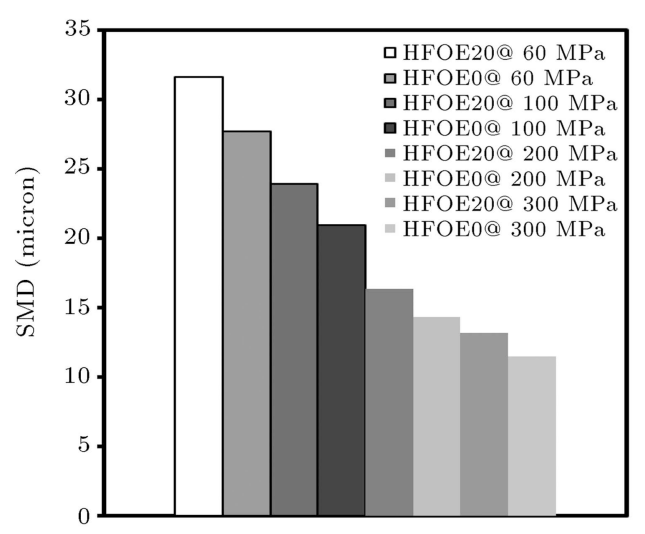

(d)

Figure 14. (a) Spray penetration length, (b) spray cone angle, (c) spray volume and (d) SMD for different injection pressure of HFOE20 and pure HFO $\left(P_{\mathrm{back}}=1.4 \mathrm{MPa}, T_{\mathrm{amb}}=298 \mathrm{~K}\right)$.

HFOE0 and HFOE20, especially for HFOE20 and for a pressure increase of $10 \mathrm{MPa}$ to $200 \mathrm{MPa}$.

According to Figure 14(d), lower SMD value is achieved by higher injection pressure for both fuels. Hence, the effect of higher SMD of the emulsified fuels can be reduced by higher injection pressure. Due to growth of instabilities on the liquid spray surface, better atomization procedure is anticipated for higher injection pressure for both fuels. The obtained results of SMD are in accordance with those of study of Wang et al. [15].

\subsection{Effect of different back pressure on emulsified fuel}

Based on Table 5, the effects of three back pressures are studied on spray characteristics and morphology of HFOE20 as emulsified fuel and HFOE0.

Liquid spray structure for different back pressures of HFOE20 at $1.5 \mathrm{~ms}$ ASOI and injection pressure of $60 \mathrm{MP}$ is presented in Figure 15. As evident in Figure 15, due to the shock wave in ambient air against the injected spray, sharper spray tip is detectable for $1.4 \mathrm{MPa}$. Moreover, more compact spray structure

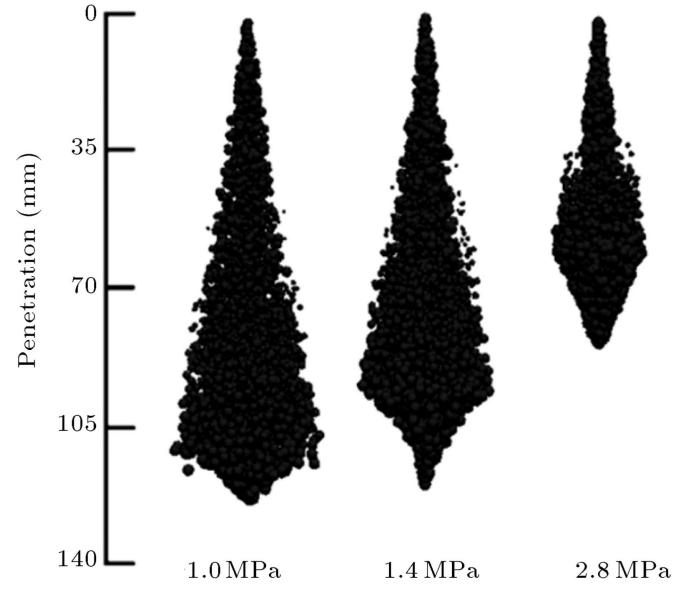

Figure 15. Liquid spray structure for different back pressures of HFOE20 at $1.5 \mathrm{~ms}$ ASOI $\left(P_{\text {inj }}=60 \mathrm{MPa}\right.$, $\left.T_{\mathrm{amb}}=298 \mathrm{~K}\right)$.

with conical tip is achieved for HFOE20 at back pressure of $2.8 \mathrm{MPa}$. These phenomena can be the result of an increase in the aerodynamic resistance of ambient gaseous air in the face of liquid spray structure.

Microscopic and macroscopic characteristics of 
Table 5. Cases of different back pressures for HFOE0 and HFOE20.

\begin{tabular}{lcc}
\hline \multicolumn{1}{c}{ Case study } & $\begin{array}{c}\text { Back pressure } \\
(\mathbf{M P a})\end{array}$ & $\begin{array}{c}\text { Other environmental } \\
\text { characteristics }\end{array}$ \\
\hline HFOE20 @ $1 \mathrm{MPa}$ & 1 & \\
HFOE20 @ $1.4 \mathrm{MPa}$ & 1.4 & Injection pressure $=60 \mathrm{MPa}$ \\
HFOE0@1.4 MPa & 1.4 & Ambient temperature $=298 \mathrm{~K}$ \\
HFOE20@ $2.8 \mathrm{MPa}$ & 2.8 & \\
HFOE0 @ $2.8 \mathrm{MPa}$ & 2.8 & \\
\hline
\end{tabular}

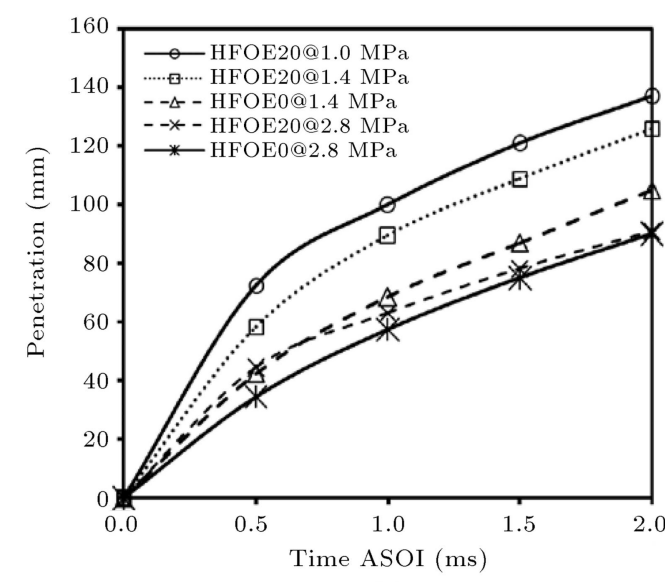

(a)

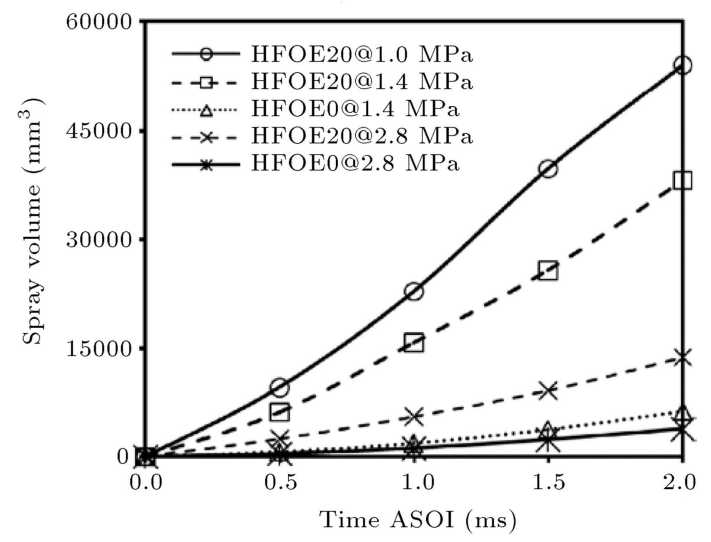

(c)

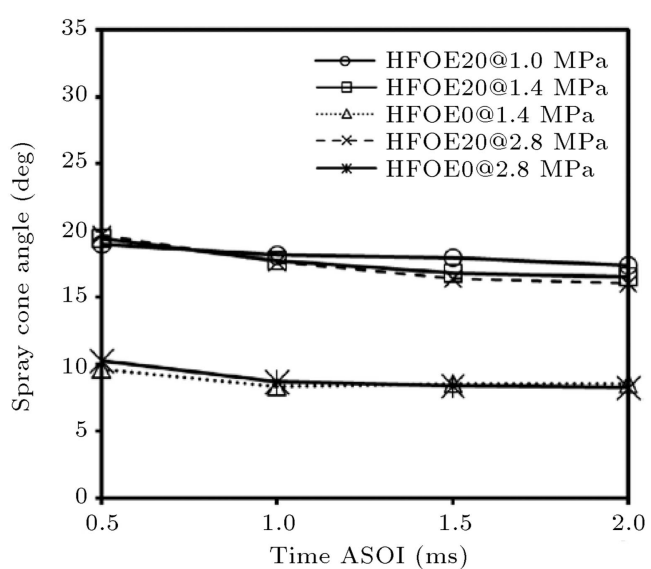

(b)

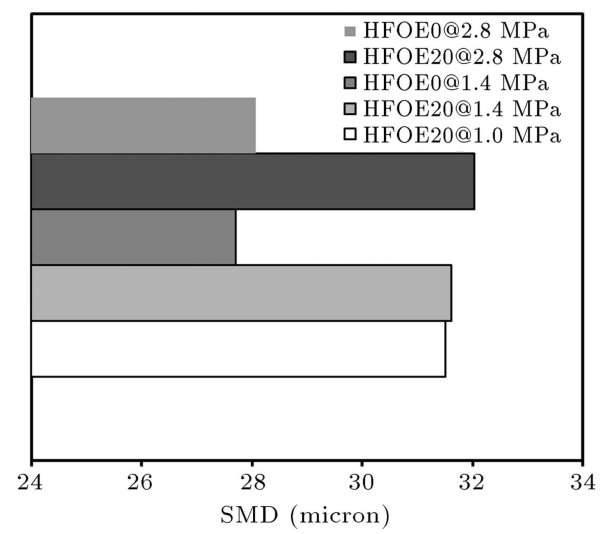

(d)

Figure 16. (a) Spray penetration length, (b) spray cone angle, (c) spray volume, and (d) SMD for different back pressures of HFOE20 and pure HFO $\left(P_{\mathrm{inj}}=60 \mathrm{MPa}, T_{\mathrm{amb}}=298 \mathrm{~K}\right)$.

HFOE0 and HFOE20 are illustrated in Figure 16 for different back pressures. Based on Figure 16(a), it can be concluded that with an increase in chamber back pressure, spray penetration length is decreased due to the reinforcement of the ambient fluid resistance. On the other hand, reduction rate of penetration from back pressure of $1.4 \mathrm{MPa}$ to $2.8 \mathrm{MPa}$ for HFOE20 is more visible compared to back pressure reduction for pure HFOE0.

Also, according to Figure 16(b), one can observe that different back pressures have no significant influence on the spray cone angle for both HFOE0 and HFOE20, especially until $1 \mathrm{~ms}$ ASOI. In addition, similar to the penetration length, greater spray volume for HFOE20 at atmospheric back pressure of $1 \mathrm{MPa}$ is detectable in Figure 16(c).

On the other hand, based on Figure 16(d), higher back pressure leads to greater value of SMD for both HFOE0 and HFOE20 fuels. The reason for this phenomenon can be found in the delay of atomization procedure with aerial aerodynamic force due to the higher back pressure.

\subsection{Effect of different ambient temperature on emulsified fuel}

The spray penetration, spray cone angle, and spray volume for two different chamber ambient temperatures under the conditions of Table 6 are presented 
Table 6. Cases of different temperature for HFOE20.

\begin{tabular}{ccl}
\hline Case study & $\begin{array}{c}\text { Ambient temperature } \\
(\mathbf{K})\end{array}$ & $\begin{array}{c}\text { Other environmental } \\
\text { characteristics }\end{array}$ \\
\hline Ambient air temperature $=298 \mathrm{~K}$ & 298 & $\begin{array}{l}\text { Injection pressure }=60 \mathrm{MPa} \\
\text { Ambient back pressure }=1.4 \mathrm{MPa}\end{array}$ \\
\hline
\end{tabular}

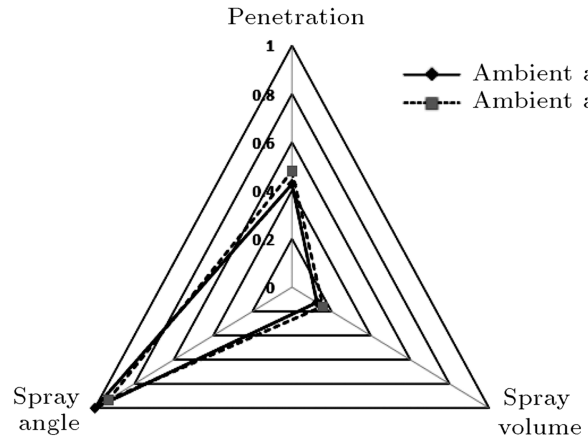

(a) $0.5 \mathrm{~ms}$ ASOI

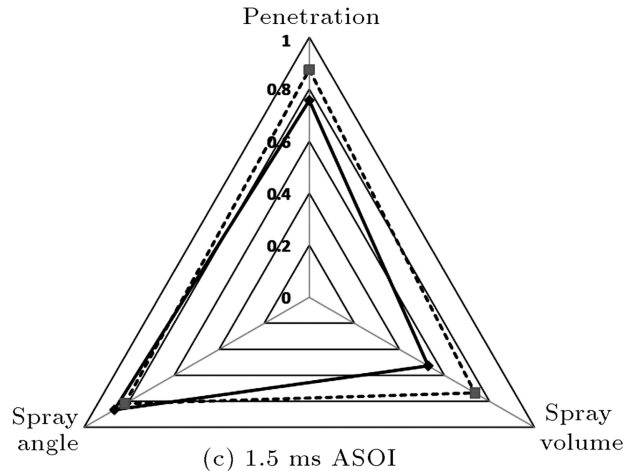

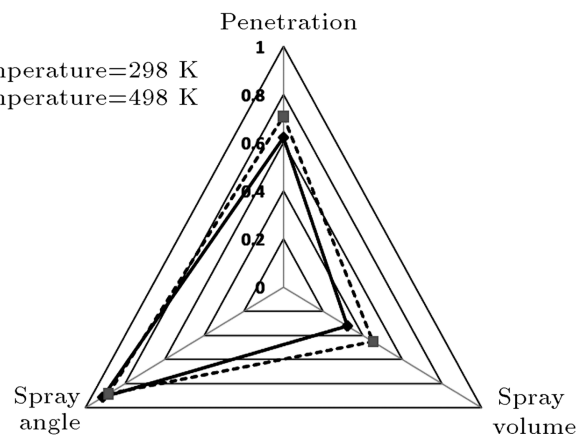

(b) $1 \mathrm{~ms}$ ASOI

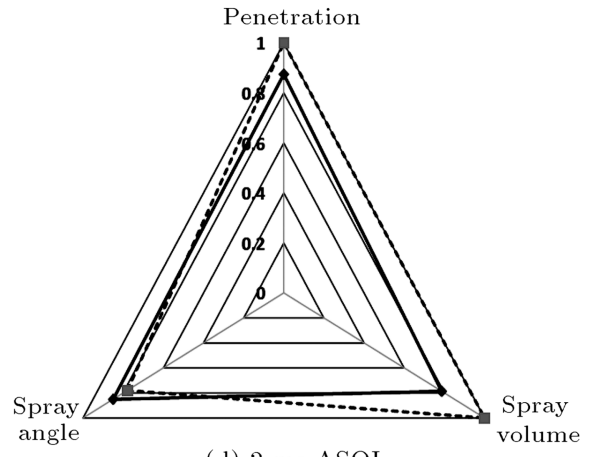

(d) $2 \mathrm{~ms}$ ASOI

Figure 17. Spray penetration length, spray cone angle, and spray volume for different ambient temperatures of HFOE20 $\left(P_{\text {back }}=1.4 \mathrm{MPa}, P_{\text {inj }}=60 \mathrm{MPa}, T_{\mathrm{amb}}=298 \mathrm{~K}\right)$.

in Figure 17. Based on Figure 17, one can observe that temporal spray penetration length increases for HFOE20 by an increase in chamber ambient temperature from $298 \mathrm{~K}$ to $498 \mathrm{~K}$. Also, an increase in the spray penetration length leads to greater growth rate in timeline. However, lower spray cone angle is revealed by increasing ambient temperature from $298 \mathrm{~K}$ to $498 \mathrm{~K}$.

Moreover, greater spray volume is achieved by the ambient temperature increase.

Furthermore, based on Figure 18, chamber ambient temperature increasing from $298 \mathrm{~K}$ to $498 \mathrm{~K}$ leads to a decrease in SMD for HFOE20. This reduction

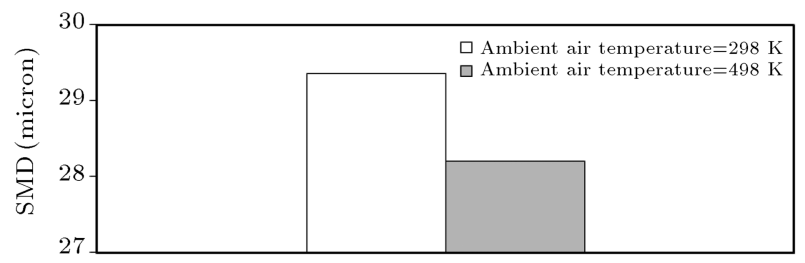

Figure 18. SMD for different ambient temperature of HFOE20 $\left(P_{\text {back }}=1.4 \mathrm{MPa}, P_{\text {inj }}=60 \mathrm{MPa}\right.$, $\left.T_{\mathrm{amb}}=298 \mathrm{~K}\right)$. is considerable and leads to half value of the SMD at higher ambient temperature. Reduction of SMD is due to an increase in injected fuel (HFOE20) temperature by an increase in ambient temperature. As a result of the temperature rise in HFOE20, its surface tension, viscosity, and density are decreased [36].

On the other hand, lower viscosity increases the instabilities required for the injected fuel jet to breakup. This accelerates the atomization procedure and leads to lower SMD value. In addition, reduction of the injected fuel density directly impacts the atomization procedure [40]. Moreover, higher surface tension acts against the formation of smaller droplets from the liquid fuel [39]. Therefore, a decrease in surface tension improves the atomization procedure and results in lower SMD.

Based on the stated reasons, a decrease in SMD for HFOE20 can be expected due to an increase in chamber ambient temperature. Meanwhile, this decrease in SMD value by ambient temperature increase is consistent with the result of the study of Park et al. [20]. 
Table 7. A summary of the observations for different applied fuels.

\begin{tabular}{|c|c|c|}
\hline Spray parameter & $\begin{array}{l}\text { Substitution of HFOE20 instead } \\
\text { of HFO }\left(P_{\text {inj }}=60 \mathrm{MPa},\right. \\
\left.P_{\text {back }}=1.4 \mathrm{MPa}, T_{\text {amb }}=298 \mathrm{~K}\right)\end{array}$ & $\begin{array}{c}\text { Adding water from } 5 \% \text { to } 20 \% \\
\text { in emulsion }\left(P_{\text {inj }}=60 \mathrm{MPa},\right. \\
\left.P_{\text {back }}=1.4 \mathrm{MPa}, T_{\mathrm{amb}}=298 \mathrm{~K}\right)\end{array}$ \\
\hline Spray penetration & $23.75 \% \uparrow$ & $21.47 \% \uparrow$ \\
\hline Spray cone angle & $100.81 \% \uparrow$ & $4.9 \% \uparrow$ \\
\hline Spray volume & $57.92 \% \uparrow$ & $2.87 \% \uparrow$ \\
\hline SMD & $14.09 \% \uparrow$ & $9.43 \% \uparrow$ \\
\hline
\end{tabular}

$\uparrow$ represents higher comparative value.

Table 8. A summary of the observations for different ambient conditions.

\begin{tabular}{|c|c|c|c|}
\hline Spray parameter & $\begin{array}{c}\text { Injection pressure } \\
\text { enhancement } \\
\text { from } 60 \mathrm{MPa} \text { to } 300 \mathrm{MPa}^{\mathrm{a}}\end{array}$ & $\begin{array}{c}\text { Back pressure } \\
\text { enhancement } \\
\text { from } 1 \mathrm{MPa} \text { to } 2.8 \mathrm{MPa}^{\mathrm{b}}\end{array}$ & $\begin{array}{c}\text { Ambient temperature } \\
\text { enhancement } \\
\text { from } 298 \mathrm{~K} \text { to } 498 \mathrm{~K}^{\mathrm{c}}\end{array}$ \\
\hline Spray penetration & $27.35 \% \uparrow$ & $55.5 \% \downarrow$ & $14.27 \% \uparrow$ \\
\hline Spray cone angle & $6.53 \% \uparrow$ & $3.94 \% \downarrow$ & $24.74 \% \uparrow$ \\
\hline Spray volume & $92.0 \% \uparrow$ & $250.06 \% \downarrow$ & $2.87 \% \uparrow$ \\
\hline SMD & $140.66 \% \downarrow$ & $1.68 \% \uparrow$ & 4. $03 \% \downarrow$ \\
\hline
\end{tabular}

${ }^{\mathrm{a}} P_{\text {back }}=1.4 \mathrm{MPa}, T_{\mathrm{amb}}=298 \mathrm{~K} ;{ }^{\mathrm{b}} P_{\text {inj }}=60 \mathrm{MPa}, T_{\mathrm{amb}}=298 \mathrm{~K} ;{ }^{\mathrm{c}} P_{\text {back }}=1.4 \mathrm{MPa}, P_{\text {inj }}=60 \mathrm{MPa}$.

$\uparrow$ Represents higher comparative value; $\downarrow$ Represents lower comparative value;

The average of the relative influence of water addition to pure HFO fuel and the effect of adding water from $5 \%$ to $20 \%$ in emulsion are summarized in Table 7. Also, a summary of the observations for different ambient conditions and different injection pressures of HFOE20 is presented in Table 8.

Based on the demonstrated results of Tables 7 and 8, larger spray penetration, spray cone angle, and spray volume in emulsified fuels offer a better air-fuel mixture. Furthermore, smaller value of SMD represents a better atomization procedure at lower back pressure and higher temperature.

\section{Conclusions}

Non-reacting spray characteristics of the emulsified fuels (alternative fuel with tha aim of increasing the fuel efficiency) are assessed in the present study.

For this purpose, three different volume percentages $(5 \%, 15 \%$, and $20 \%)$ of water in emulsion are used in comparison with pure HFO. Moreover, behavior of the selected emulsified fuel and pure HFO are evaluated under different injection pressure, back pressures, and ambient temperatures. For evaluation of the spray characteristics, the microscopic and macroscopic spray criteria are investigated after the analyses of the nondimensional numbers including Weber, Ohnesorge, and Reynolds.

To carry out the intended study, the open source CFD toolbox of OpenFOAM is utilized. EulerianLagrangian multiphase scheme, Hybrid breakup model of KH-RT, and Lagrangian Particle Tracking (LPT) method are used for turbulence modeling in Eulerian scheme; standard model of $k-\varepsilon$ in RANS is performed.

First, a grid sensitivity analysis for the HFO is conducted. Then, spray penetration length and spray cone angle for HFO are validated with appropriate accordance. Based on the obtained computational results, spray penetration length of the emulsified fuels is larger than that of pure HFO. Moreover, values of spray cone angle and spray volume increase by replacing the pure HFO by emulsified fuels. However, due to increase in surface tension and significant decrease in dynamic viscosity of the emulsified fuels, larger SMD value is measured for the emulsified fuels. It was also concluded that by increasing the volumetric percentage of water in the emulsified fuel, the macroscopic spray criteria are improved.

On the other hand, with an increase in injection pressure from $60 \mathrm{MPa}$ to ultra-high value of $300 \mathrm{MPa}$, the spray penetration length is increased for both emulsified fuel (HFOE20) and pure HFO. Also, due to the increase in surface tension of the emulsified fuels, an increase in injection pressure has negligible influence on the spray cone angle of the emulsified fuels, but leads to growing spray volume for both HFOE0 and HFOE20, especially for HFOE20, when the injection pressure increases from $100 \mathrm{MPa}$ to $200 \mathrm{MPa}$. Meanwhile, lower SMD value is achieved by higher injection pressure for both fuels.

Based on the studies performed on the effect of different back pressures, one can easily see that with an increase in chamber back pressure, spray penetration length is decreased. Also, reduction rate of penetration 
from back pressure of 1.4 MPa to 2.8 MPa for HFOE20 is more visible compared to back pressure reduction for pure HFOE0. On the other hand, higher back pressures lead to greater value of SMD for both HFOE0 and HFOE20 fuels. This can be attributed to the lag of breakup procedure with aerial aerodynamic force due to higher back pressure.

From another point of view, an increase in temporal spray penetration length is observed for HFOE20 by increasing the chamber ambient temperature from $298 \mathrm{~K}$ to $498 \mathrm{~K}$. However, a lower spray cone angle is displayed by increasing the ambient temperature from $298 \mathrm{~K}$ to $498 \mathrm{~K}$. Furthermore, due to the decrease in surface tension, viscosity, and density of HFOE20, an increase in chamber ambient temperature leads to the reduction of SMD for HFOE20.

Overall, it is concluded that the emulsified fuel represents a better air-fuel mixture because of larger spray penetration, spray cone angle, and spray volume. Also, an improved atomization procedure with lower SMD value of emulsified fuel can be achieved by higher injection pressure, ambient temperature, and lower back pressure.

\section{Nomenclature}

\section{Latin letters}

\section{HFO Heavy Fuel Oil;}

PM Particulate Matter;

RANS Reynolds Averaged Navier Stokes;

RMSE Root Mean Square Error;

ASOI After Start Of Injection;

SMD Sauter Mean Diameter;

SIMPLE Semi Implicit Method for Pressure Linked Equations;

LPT Lagrangian Particle Tracking;

$\dot{f}_{c o} \quad$ Contribution due to the effects of collision of the droplets;

$\dot{f}_{b r} \quad$ Contribution due to the effects of droplets breakup;

$\mathrm{We}_{l} \quad$ Liquid fuel Weber number;

$\mathrm{We}_{g} \quad$ Gas Weber number;

$u_{\text {rel }} \quad$ Relative speed between droplets and ambient gas $\left(\mathrm{m} . \mathrm{s}^{-1}\right)$;

$D_{d} \quad$ Diameter of fuel droplet $(\mathrm{m})$;

$\mathrm{Re}_{l} \quad$ Liquid fuel Reynolds number;

$r_{0} \quad$ Droplet radius before breakup (m);

$r_{c} \quad$ Radius of child droplets (m);

Oh Ohnesorge number;

T Taylor number;

$\begin{array}{ll}P_{\text {inj }} & \text { Injection pressure }(\mathrm{MPa}) ; \\ P_{\text {back }} & \text { Ambient back pressure }(\mathrm{MPa}) ; \\ T_{\text {amb }} & \text { Ambient temperature }(\mathrm{K}) .\end{array}$

\section{Greek letters}

$\Lambda_{\mathrm{KH}} \quad$ Kelvin-Helmholtz wavelength (m);

$\Lambda_{\mathrm{RT}} \quad$ Rayleigh-Taylor wavelength (m);

$\Omega_{\mathrm{KH}} \quad$ Kelvin-Helmholtz growth rate $\left(\mathrm{s}^{-1}\right)$;

$\Omega_{\mathrm{RT}} \quad$ Rayleigh-Taylor growth rate $\left(\mathrm{s}^{-1}\right)$;

$\rho_{g} \quad$ Gas density $\left(\mathrm{kg} . \mathrm{m}^{-3}\right)$;

$\rho_{l} \quad$ Liquid fuel density $\left(\mathrm{kg} \cdot \mathrm{m}^{-3}\right)$;

$\tau_{b u} \quad$ Characteristic time (s);

$\sigma \quad$ Surface tension $\left(\mathrm{N} . \mathrm{m}^{-1}\right)$;

$\nu_{g} \quad$ Gas kinematic viscosity $\left(\mathrm{m} . \mathrm{s}^{-1}\right)$;

$\omega \quad$ Instability wave growth rate.

\section{References}

1. Majewski, W.A. and Khair, M.K., Diesel Emissions and Their Control, 1st Ed., Warrendale, PA: SAE International (2006).

2. Plee, S.L., Ahmad, T. and Myers, J.P. "Flame temperature correlation for the effects of exhaust gas recirculation on diesel particulate and NOx emissions", SAE Technical Paper No. 811195 (1981).

3. Plee, S.L., Ahmad, T., Myers, J.P. and Faeth, G.M. "Diesel NOx emissions - A simple correlation technique for intake air effects", P. Combust Inst., 19, pp. 1495502 (1982).

4. Musculus, M.P.B., Miles, P.C. and Pickett, L.M. "Conceptual models for partially premixed low-temperature diesel combustion", Prog. Energ Combust, 39, pp. 24683 (2013).

5. Jiménez-Espadafor, F.J., Torres, M., Velez, J.A., Carvajal, E. and Becerra, J.A. "Experimental analysis of low temperature combustion mode with diesel and biodiesel fuels: A method for reducing NOx and soot emissions", Fuel Process Technol., 103, pp. 57-63 (2012).

6. Wamankar, A.K. and Murugan, S. "Experimental investigation of carbon black-water-diesel emulsion in a stationary DI diesel engine", Fuel Process Technol., 125, pp. 258-266 (2014).

7. Musculus, M., Dec, J., Tree, D., Daly, D. and et al. "Effects of water-fuel emulsions on spray and combustion processes in a heavy-duty DI diesel engine", SAE Technical Paper No. 2002-01-2892 (2002).

8. Selim, M.Y.E and Ghannam, M.T. "Combustion study of stabilized water-in-diesel fuel emulsion", Energ Source Part A, 32(3), pp. 256-74 (2010).

9. Huo, M., Lin, S., Liu, H. and Lee, C.F.F. "Study on the spray and combustion characteristics of wateremulsified diesel", Fuel, 123, pp. 218-29 (2014). 
10. Ballester, J.M., Fueyo, N. and Dopazo, C. "Combustion characteristics of heavy oil-water emulsions", Fuel, 75, pp. 695-705 (1996).

11. Park, J.W., Huh, K.Y. and Lee, J.H. "Reduction of NOx, smoke and brake specific fuel consumption with optimal injection timing and emulsion ratio of wateremulsified diesel", P. I. Mech. Eng. D-J Aut., 21, pp. 83-93 (2001).

12. Rakopoulos, D.C., Rakopoulos, C.D., Papagiannakis, R.G. and Kyritsis, D.C. "Combustion heat release analysis of ethanol or N-butanol diesel fuel blends in heavy-duty DI diesel engine", Fuel, 90, pp. 1855-67 (2011).

13. Nowruzi, H., Ghadimi, P. and Yousefifard, M.A. "Numerical study of spray characteristics in medium speed engine fueled by different Hfo/N-butanol blends", International Journal of Chemical Engineering (2014). http://dx.doi.org/10.1155/2014/702890

14. Nishida, K., Zhang, W. and Manabe, T. "Effects of micro-hole and ultra-high injection pressure on mixture properties of D.I. diesel spray", SAE Technical Paper No. 2007-01-1890 (2007).

15. Wang, X., Huang, Z., Kuti, O.A., Zhang, W. and Nishida, K. "Experimental and analytical study on biodiesel and diesel spray characteristics under ultrahigh injection pressure", Int. J. Heat Fluid Fl., 31, pp. 659-66 (2010).

16. Yousefifard, M., Ghadimi, P. and Nowruzi, H. "Numerical investigation of the effects of chamber back pressure and temperature on HFO spray characteristics", Int. J. Automot. Techn., 16(2), pp. 339-349 (2015). (DOI 10.1007/s12239-015-0036-z).

17. Prakash, R.S., Gadgil, H. and Raghunandan, B.N. "Breakup processes of pressure swirl spray in gaseous cross-flow", Int. J. Multiphas. Flow, 66, pp. 79-91 (2014).

18. Yang, G.X. and Chn, J.S. "Experimental study of the effect of high back-pressure on the atomization of a plain jet injector under coaxial air flow", Aerosol Sci. Tech., 12, pp. 903-10 (1990).

19. Roisman, I.V., Araneo, L. and Tropea, C. "Effect of ambient pressure on penetration of a diesel spray", Int. J. Multiphas Flow, 33, pp. 904-20 (2007).

20. Park, S.H., Kim, H.J. and Lee, C.S. "Comparison of experimental and predicted atomization characteristics of high-pressure diesel spray under various fuel and ambient temperature", J. Mech. Sci. Technol., 24, pp. 1491-99 (2010).

21. Chen, X., Liu, Y. and Yang, V. "Effect of back pressure on internal flow dynamic and spray characteristics of liquid swirl injector", 49th AIAA Aerospace Sciences Meeting Including the New Horizons Forum and Aerospace Exposition, Orlando, Florida (2011).

22. Chitsaz, I., Saidi, M.H. and Mozafari, A.A. "CFD based optimization of the mixture formation in spark ignition direct injection CNG engin", Scientia Iranica $B, 21(5)$, pp. 1621-1624 (2014).
23. Mohammadebrahima, A., Kazemzadeh Hannania, S. and Shafii, B. "Investigation into the efect of intake port geometric parameters and blockage on flow coefficient and in-cylinder flow: Application to engine port design", Scientia Iranica B, 21(2), pp. 438-448 (2014).

24. Yadollahi, B. and Boroomand, M. "Multidimensional modeling of CNG direct injection and mixture preparation in a SI engine cylinder", Scientia Iranica B, 20(6), pp. 1729-1741 (2013).

25. Gjesing, R., Hattel, J. and Fritsching, U. "Coupled atomization and spray modeling in the spray forming process using OpenFOAM", Eng. Appl. of Comp. Fluid Mech., 3, pp. 471-86 (2009).

26. Yousefifard, M., Ghadimi, P. and Mirsalim, M. "Numerical simulation of biodiesel spray under ultra-high injection pressure using OpenFOAM", J. Braz. Soc. Mech. Sci. (2014).

27. O'Sullivan, C., Investigation of the NOx and PM Emissions from a Diesel Engine Operating on NanoEmulsified Fuels, University College of Dublin, Ireland (1997).

28. Chen, G. and Tao, D. "An experimental study of stability of oil-water emulsion", Fuel Process Technol., 86(5), pp. 499-508 (2005).

29. Scarpete, D. "Diesel-water emulsion, an alternative fuel to reduce diesel engine emissions. A review", Machines, Technologies, Materials, 7, pp. 9-13 (2013).

30. Jiang, X., Siamas, G.A., Jagus, K. and Karayiannis, T.G. "Physical modeling and advanced simulations of gas-liquid two-phase jet flows in atomization and sprays", Prog. Energ. Combust., 36, pp. 131-67 (2010).

31. Reitz, R.D. and Diwakar, J. "Effect of drop breakup on fuel sprays", SAE Technical Paper No. 860469 (1986).

32. Reitz, R.D. and Diwakar, R. "Structure of highpressure fuel sprays", SAE Technical Paper No. 870598 (1987).

33. Reitz, R.D. "Modeling atomization processes in high pressure vaporizing sprays", Atomization and Spray Technology, 3, pp. 309-37 (1987).

34. Bellman, R. and Pennington, R. "Effects of surface tension and viscosity on Taylor instability", Q. Appl. Math., 12, pp. 151-62 (1954).

35. Ghasemi, A., Fukuda, K., Balachandar, R. and Barron, R.M. "Numerical investigation of spray characteristics of diesel alternative fuels", SAE Technical Paper No. 2012-01-1265 (2012).

36. Fink. C., Buchholz, B., Niendorf, M. and Harndorf, H. "Injection spray analyses from medium speed engines using marine fuels", In Proceedings of the 22nd European Conference on Liquid Atomization and Spray Systems (ILASS '08), Lake Como, Italy, September (2008).

37. Pickett, L., Manin, J., Payri, R., Bardi, M. and Gimeno, J. "Transient rate of injection effects on spray development", SAE Technical Paper No. 2013-24-0001 (2013). 
38. Hardalupas, Y., Taylor, A.M.K.P and Whitelaw, J.H "Characteristics of the spray from a diesel injector", Int. J. Multiphas. Flow, 18, pp. 159-79 (1992).

39. Lefebvre, A.H., Atomization and Sprays, 1st Ed., New York, Hemisphere Publishing Corporation (1989).

40. Ejim, C.M., Fleck, B.A. and Amirfazli, A. "Analytical study for atomization of biodiesels and their blends in a typical injector: Surface tension and viscosity effects", Fuel, 86(10-11), pp. 1534-1544 (2007).

\section{Biographies}

Hashem Nowruzi was born in Tehran, Iran in 1990. He received his BSc degree in Marine Engineering from Amirkabir University of Technology (AUT), Tehran, Iran, in 2012. He then received his MS degree in Ship Hydrodynamics in Dept. of Marine Technology, from Amirkabir University of Technology, in 2014. $\mathrm{He}$ is currently a PhD student in the same field and university. His research interests include CFD modeling of hydrodynamics phenomena and high pressure diesel injection. He has co-authored 7 scientific papers in the field of computational fluid dynamics and hydrodynamics.

Parviz Ghadimi received his $\mathrm{PhD}$ in Mechanical Engineering in 1994 from Duke University, USA. He served one year as a Research Assistant Professor in M.E. and six years as a Visiting Assistant Professor in Mathematics Department in Duke. He joined the Department of Marine Technolgy in Amirkabir University of Technology (Tehran, Iran) in Fall 2005 as an Assistant Professor of Hydromechanics, and is currently a Professor and Associate Chair of Graduate Studies in the same department. His main research interests include hydrodynamics, hydroacoutics, thermohydrodynamics, and CFD. Dr. Ghadimi has authored several scientific papers in these fields and has also authored two textbooks in Farsi: Applied Computational Fluid Dynamics and Engineering Mathematics. 